\title{
Predicting of Impact Strength and Elastic Modulus of Polypropylene/EPDM/Graphene/Glass Fiber Nanocomposites by Response Surface Methodology
}

\author{
Meysam Nouri Niyaraki, Faramarz Ashenai Ghasemi, Ismail Ghasemi, Sajjad Daneshpayeh
}

\begin{abstract}
In the present manuscript, Response Surface Method (RSM) of the experimental planning was applied to optimize the mechanical properties such as impact strength and elastic modulus of polypropylene (PP)/ethylene propylene dine monomer (EPDM) /grapheme Nano sheets (GnPs)/ glass fiber hybrid nanocomposites. According to a BoxBehnken method, three levels of parameters were used for EPDM (5, 10 and $15 \mathrm{wt} . \%), \mathrm{GnPs}(0,1$ and $2 \mathrm{wt} . \%)$ and glass fiber (10, 20 and 30 wt.\%). In addition, specimens were studied using differential scanning calorimeter (DSC) and scanning electron microscopy (SEM) to see their morphology and thermal properties. It was discovered that GnPs, glass fiber and EPDM played an important role in impact strength and elastic modulus of the nanocomposites. To reach the maximum value of the impact strength and elastic modulus simultaneously, the best amount of additives was about $0.82 \mathrm{wt} . \%$ of $\mathrm{GnPs}, 30 \mathrm{wt} \%$ of glass fiber and $15 \mathrm{wt} . \%$ of EPDM. The gained $R^{2}$ values and the corresponding diagrams showed a desirable accordance (above 0.93 for all the responses) with the experiments and those guessed by the RSM.
\end{abstract}

Keywords: elastic modulus; graphene Nano sheets; impact strength; polypropylene; RSM (Response Surface Method)

\section{INTRODUCTION}

Polypropylene (PP) is a thermoplastic polymer that shows better thermal and mechanical properties compared to other industrial polymers. PP can be a good candidate for using in the packaging of food products, medicine, electrical tools, and automotive industries due to proper manufacturing cost, good recyclability and low weight $[1,2]$. Nevertheless, some weaknesses such as its low stiffness and toughness has limited some of its applications [3]. However, the mechanical properties of PP could be improved by blending it with other polymers or nanoscale materials [4].

Blending of polymers together is an appreciate way to improve the toughness of them, which is not easily achieved by polymerization process [5]. Researchers have used many polymers including linear low density polyethylene (LLDPE) [6], low density polyethylene (LDPE) [7], high density polyethylene (HDPE) [8], ethylene propylene diene monomer (EPDM) [9] and other elastomeric polymers to modify the toughness of the PP. In some cases, EPDM is used for toughening of PP [10]. Blending PP by EPDM have reached great significant for commercial interest for structural adaptability. Recently, many researches have been published to investigating the mechanical properties the PP/EPDM blends [11, 12]. Khalili et al. [13] showed that the addition of EPDM led to a nominal increase in impact strength. For example, the impact strength of $50 \mathrm{wt} . \%$ flax fiber composites increased by $8 \%$ through the addition of 10 wt.\% EPDM.

Newly, a large amount of researches have been concentrated on polymer composites having nano reinforced materials. The amount of carbon-based nano reinforcement materials is increased; from carbon nanotubes and nanofibers up to GnPs [14]. The addition of GnPs to a polymer matrix noticeably improves the material properties. In recent years, exfoliated GnPs have fascinated a large consideration because of their special characteristics [15]. Embedding low percentages of GnPs in PP matrix has been studied by many researches [16-18] and their results show improvement in the mechanical properties.
Recently, glass fibers are widely used as the reinforcement for composite materials because of their various advantages compared to natural fibers. The glass fibers have benefits such as their high temperature strength, corrosion stability, good dimensional durability, extremely light, solid material, support of the continuous production process of automotive industry and almost no moisture absorption [19, 21]. By the addition fibers to a matrix, the mechanical properties respect to base polymer increases properly. Güllü et al. found that polyamide reinforced with glass fiber exhibited an improving in their tensile and impact strength [22]. Response surface methodology (RSM) is an effective approach to develop, improve and optimize different procedures [23]. RSM supplies the interactions between variables better than any other procedures. Therefore, using RSM in optimization offers more appropriate data by a minimum of experiments. Up to now, experiments have been done in a way to study only one parameter at a time (neglecting the effects of the other parameters). It must be also noted that it is hard to find the best values of factors to guess the mechanical characteristics. To solve this, design of experiment (DOE) methodology was applied. This method permits of altering the value of factors altogether rather than one at a time and achieving the interaction between of the factors [24].

Considering the previous researches, one sees that the simultaneous presence of a rubber, a nanomaterial and glass fibers in a polymer matrix leads to an improve in its mechanical properties. The main goal of the present work was to use DOE methodology to study the modeling procedure and investigate the parameters effects of GnPs nanoparticles, glass fibers and EPDM on the impact resistance and modulus of elasticity of PP/ EPDM / GnPs / glass fiber nanocomposites at three levels. The design of experiments was done by the box-Behnken method and samples were prepared using a melt mixing method. Also, for each factor the optimal values were computed. Finally, the effect of GnPs on thermal properties of PP was investigated. 


\section{EXPERIMENTAL}

\subsection{Materials}

The PP had a melt flow index (MFI) of $18 \mathrm{~g} / 10 \mathrm{~min}$ and density of $0.918 \mathrm{~g} / \mathrm{cm}^{3}$. This material was provided from Arak Petrochemical Company (Iran). The graphene (C750grade) provided from XG Science (USA). This type of GnPs were the sub-micron sheets that their diameters were below $2 \mathrm{~mm}$, a few nanometer thickness and $750 \mathrm{~m}^{2} / \mathrm{g}$ average surface area. In this study, the glass fibers type $\mathrm{E}$ by the average length of $6 \mathrm{~mm}$, the average diameter of $14 \mu \mathrm{m}$ and density of $2.25 \mathrm{~g} / \mathrm{cm}^{3}$ were purchased from Korean Chemical Contents Company. EPDM (KEP270 type) with the density of $0.9 \mathrm{~g} / \mathrm{cm}^{3}$ and including $57 \mathrm{wt} . \%$ ethylene / $4.5 \mathrm{wt} . \%$ dine monomer was provided by Kumho Company (South Korea).

\subsection{Preparation of Samples}

The samples were made with melt-process by an internal mixer (type Haake-HBI SYS 90) at $60 \mathrm{rpm}$ and $180{ }^{\circ} \mathrm{C}$ for 10 min. After melting the PP in an internal mixer, EPDM in 5,10 and 15 wt.\% were added to it. Then, GnPs in 0,1 and 2 wt. $\%$ and the glass fiber in 10, 20 and $30 \mathrm{wt} . \%$ were added to the melt. The mixing time was considered $10 \mathrm{~min}$ for all the cases. The test samples were made using hot-press molding having a square steel mold $\left(250 \times 250 \mathrm{~mm}^{2}\right)$ in $200{ }^{\circ} \mathrm{C}$. Samples were preheated up to $200{ }^{\circ} \mathrm{C}$ at $2.5 \mathrm{MPa}$ pressure and maintained at this pressure 5 minutes. To obtain more accurate results for impact strength and elastic modulus, each of the five specimens was prepared per combination.

\subsection{Design of Experiments (DOE)}

Box-Behnken system was applied in the present research to design of the experiments. Minitab@ ${ }^{\circledR} 17$ was used for modeling of a design matrix and also to investigate on the experimental data. Input parameters including glass fiber, GnPs, and EPDM are shown in Tab. 1. In According to BoxBehnken method, 15 experiments having 3 center points were carried (Tab. 2).

Table 1 Variables and their levels in experimental design. \begin{tabular}{|l|l|l|l|}
\hline Variables (wt.\%) & Low level (-1) & Middle level (0) & High level (1) \\
\hline
\end{tabular}

\begin{tabular}{|l|c|c|c|}
\hline GnPs $\left(X_{1}\right)$ & 0 & 1 & 2 \\
\hline Glass fiber $\left(X_{2}\right)$ & 10 & 20 & 30 \\
\hline EPDM $\left(X_{3}\right)$ & 5 & 10 & 15 \\
\hline
\end{tabular}

The important field of RSM is optimization methods to find an amount of variables that give a desirable response. The second-order model applied in RSM shown is:

$$
\begin{aligned}
& Y=\alpha_{0}+\alpha_{1} X_{1}+\alpha_{2} X_{2}+\alpha_{3} X_{3}+\alpha_{11} X_{1}^{2}+\alpha_{22} X_{2}^{2}+ \\
& +\alpha_{33} X_{3}^{2}+\alpha_{12} X_{1} X_{2}+\alpha_{13} X_{1} X_{3}+\alpha_{23} X_{2} X_{3}
\end{aligned}
$$

here $Y$ is the response; $X_{1}, X_{2}$ and $X_{3}$ are the variables; $\alpha_{0}$ is the constant term; $\alpha_{1}, \alpha_{2}$ and $\alpha_{3}$ are the coefficients of the polynomial linear effects; $\alpha_{11}, \alpha_{22}$ and $\alpha_{33}$ are the coefficients of quadratic effect; and $\alpha_{12}, \alpha_{13}$ and $\alpha_{23}$ are the coefficients of the polynomial interaction effect. In current work, the relation between $X_{1}(\mathrm{GnPs}), X_{2}$ (glass fiber) and $X_{3}$ (EPDM) as independent variables and the response $\mathrm{Y}$ as a model for the characteristics is found according to Eq. (1).

Table 2 Box-Behnken experimental design

\begin{tabular}{|c|c|c|c|}
\hline Experiment run & GnPs (wt.\%) & Glass fiber (wt.\%) & EPDM (wt.\%) \\
\hline 1 & 0 & 10 & 10 \\
\hline 2 & 2 & 10 & 10 \\
\hline 3 & 0 & 30 & 10 \\
\hline 4 & 2 & 30 & 10 \\
\hline 5 & 0 & 20 & 5 \\
\hline 6 & 2 & 20 & 5 \\
\hline 7 & 0 & 20 & 15 \\
\hline 8 & 2 & 20 & 15 \\
\hline 9 & 1 & 10 & 5 \\
\hline 10 & 1 & 30 & 5 \\
\hline 11 & 1 & 10 & 15 \\
\hline 12 & 1 & 30 & 15 \\
\hline 13 & 1 & 20 & 10 \\
\hline 14 & 1 & 20 & 10 \\
\hline 15 & 1 & 20 & 10 \\
\hline
\end{tabular}

Tensile and impact test results in fifteen different modes based on Box-Behnken deign method with three repetitions for each compound is shown in Tab. 3 .

Table 3 Impact strength and elongation at break experimental results

\begin{tabular}{|c|c|c|c|c|}
\hline \multirow{2}{*}{$\begin{array}{c}\text { Experiment } \\
\text { run }\end{array}$} & \multicolumn{2}{|c|}{ Elastic Modulus } & \multicolumn{2}{c|}{ Impact Strength } \\
\cline { 2 - 5 } & $\begin{array}{c}\text { Values } \\
(\mathrm{MPa})\end{array}$ & $\begin{array}{c}\text { Standard } \\
\text { Deviation }\end{array}$ & $\begin{array}{c}\text { Values } \\
(\mathrm{J} / \mathrm{m})\end{array}$ & $\begin{array}{c}\text { Standard } \\
\text { Deviation }\end{array}$ \\
\hline 1 & 540 & -115.13 & 103 & -47 \\
\hline 2 & 660 & 4.87 & 138 & -12 \\
\hline 3 & 695 & 39.87 & 163 & 13 \\
\hline 4 & 720 & 64.87 & 148 & -2 \\
\hline 5 & 612 & -43.13 & 122 & -28 \\
\hline 6 & 703 & 47.87 & 136 & -14 \\
\hline 7 & 598 & -57.13 & 162 & 12 \\
\hline 8 & 642 & -13.13 & 172 & 22 \\
\hline 9 & 648 & -7.13 & 116 & -34 \\
\hline 10 & 737 & 81.87 & 158 & 8 \\
\hline 11 & 610 & -45.13 & 156 & 6 \\
\hline 12 & 712 & 56.87 & 196 & 46 \\
\hline 13 & 650 & -5.13 & 158 & 8 \\
\hline 14 & 645 & -10.13 & 160 & 10 \\
\hline 15 & 655 & -0.13 & 163 & 13 \\
\hline
\end{tabular}

\subsection{Characterization}

The elastic modulus characteristics were found by a Zwick/Roell z100 tensile test machine in accordance to ISO $527-1$, with the stretching rate of $50 \mathrm{~mm} / \mathrm{min}$ at room temperature. Notched Izod tests were done using a Santam SIT-20D pendulum impact tester. The tests were done following the ISO 179 at room temperature. To see the samples morphology, scanning electron microscopy (SEM) (WEGA-II TESCAN) was used to see the fracture surfaces of the impact samples. First, the samples covered by gold thin film at $20 \mathrm{kV}$ accelerating voltage. Differential scanning calorimetric (DSC) was used with a Netzsch DSC 200 F3 Maia device number. DSC process was done in these three phases: At the first step, the samples were heated from 25 to $200^{\circ} \mathrm{C}$ at the rate of $10^{\circ} \mathrm{C} /$ minutes. At the second step, they were maintained in this temperature for 5 minutes and cooled up to $25{ }^{\circ} \mathrm{C}$ at the cooling rate of $10{ }^{\circ} \mathrm{C} /$ minutes. At the third 
step, they were reheated up to $200{ }^{\circ} \mathrm{C}$ at the rate of 10 ${ }^{\circ} \mathrm{C} /$ minutes.

\section{RESULTS AND DISCUSSION \\ 3.1 Effects of GnPs, Glass Fiber and EPDM Compounds on Impact Strength}

To see the effect of factors on PP/ EPDM/ GnPs / glass fiber nanocomposites, analysis of variance (ANOVA) was accomplished. In an ANOVA table, the total degrees of freedom $(D F)$ are the amount of information in the data. The analysis uses that information to estimate the values of unknown population parameters. The total DF is determined by the number of observations in your sample. Also in this table the sum of squares $(S S)$ is used to predict the Fisher's variance ratio ( $F$-value). Adjusted mean squares (Adj $M S$ ) calculate how much variation a term explains. F-value is the amount of variation in the information about the average. Pvalue is the minimum of significant that its can refute the hypothesis (it must be less than 0.05) [24]. Tab. 4 shows the effect of the ANOVA for the impact strength. From Tab. 4, the linear (GnPs, glass fiber and EPDM), square (GnPs $\times$ GnPs, glass fiber $\times$ glass fiber and $\mathrm{EPDM} \times \mathrm{EPDM}$ ) and the interaction $(\mathrm{GnPs} \times$ glass fiber, $\mathrm{GnPs} \times \mathrm{EPDM}$ and glass fiber $\times$ EPDM) coefficients of the three procedure parameters according to the $p$-value were important for the impact strength. When $R^{2}$ is near to $100 \%$ means that the design is very reliable. The value of $R^{2}$ in this research showed a wellfitting of the data. $R^{2}$ Adj is a handy tool to evaluate the explanatory power of the various models. Moreover, $R^{2}$ Pred is computed by a systematic removing of any observation datasets to estimate regression equation and show that how the model forecasts the removed data. Higher amounts of $R^{2}$ Adj $(99.26 \%)$ and $R^{2}$ Pred $(95.80 \%)$ shows that the model forecasting ability is excellent.

Table 4 The impact strength ANOVA results.
\begin{tabular}{|l|c|c|c|c|c|}
\hline \multicolumn{1}{|c|}{ Source } & $D F$ & $A d j S S$ & $A d j M S$ & $F$ & $p$ \\
\hline Regression & 9 & 7785 & 865 & 210.9 & 0.000 \\
\hline Linear & 3 & 6094 & 2031 & 459.4 & 0.000 \\
\hline GnPs & 1 & 242 & 242 & 59.0 & 0.001 \\
\hline Glass Fib & 1 & 2888 & 2888 & 704.3 & 0.000 \\
\hline EPDM & 1 & 2964 & 2964 & 723.0 & 0.000 \\
\hline Square & 3 & 1061 & 353 & 86.2 & 0.000 \\
\hline GnPs $\times$ GnPs & 1 & 858 & 858 & 209.4 & 0.000 \\
\hline Glass Fib $\times$ Glass Fib & 1 & 168 & 168 & 41.0 & 0.001 \\
\hline EPDM $\times$ EPDM & 1 & 39 & 39 & 9.5 & 0.027 \\
\hline Interaction & 3 & 630 & 210 & 51.2 & 0.000 \\
\hline GnPs $\times$ Glass Fib & 1 & 625 & 625 & 152.4 & 0.000 \\
\hline GnPs $\times$ EPDM & 1 & 4 & 4 & 0.98 & 0.369 \\
\hline Glass Fib $\times$ EPDM & 1 & 1 & 1 & 0.24 & 0.642 \\
\hline$R^{2}=99.74 \%$ & \multicolumn{7}{|c|}{$R_{\text {Adj }}^{2}=99.26 \%$} & $R_{\text {Pred }}^{2}=95.80 \%$ \\
\hline
\end{tabular}

The coefficients of second order polynomial equation were found using of ANOVA outcomes and regression analysis. After omitting negligible variables, the quadratic polynomial model of is presented below:

$$
\begin{aligned}
& \text { Impact strength }=160+5.5 X_{1}+19 X_{2}+19.25 X_{3}- \\
& -12.25 X_{1}^{2}-6.75 X_{2}^{2}+3.25 X_{3}^{2}-12.25 X_{1} X_{2}
\end{aligned}
$$

In the above equation, terms without importance were omitted based on the ANOVA table. One sees that EPDM $\left(X_{3}\right)$ has the maximum effect on the impact strength respect to GnPs and glass fiber. The plots of main effects were produced to demonstrate the effect of the model outcomes.

Fig. 1 presents the main effects of the whole parameters on the impact strength. The main effects demonstrate the deviations of the mean between the high and low amounts to every parameter. According to the Fig. 1, by increasing the $\mathrm{GnPs}$, the impact strength increases $14 \%$ and, then, it decreases up to $8 \%$. This increase belongs to GnPs condensations that prevents the crack propagation. It must be noted that some of the crack propagation energy is used to pull out the GnPs from the PP matrix. This loss of energy increases the impact strength $[25,26]$. As previously mentioned, the small amount of the GnPs have a positive reinforcing effect. But, in high GnPs amounts, the agglomerations do as the points of cracks initiations which reduce the impact strength [25]. In addition, due to the Fig. 1 , increasing of glass fiber increases the impact strength up to $26 \%$, i.e. for the effect of fiber in wasting the energy of crack propagation in the specimens, increases the impact strength [27]. Also, according to Fig. 1, an increase in EPDM increased the impact strength by $29 \%$ because of flexibility of EPDM at low temperatures.

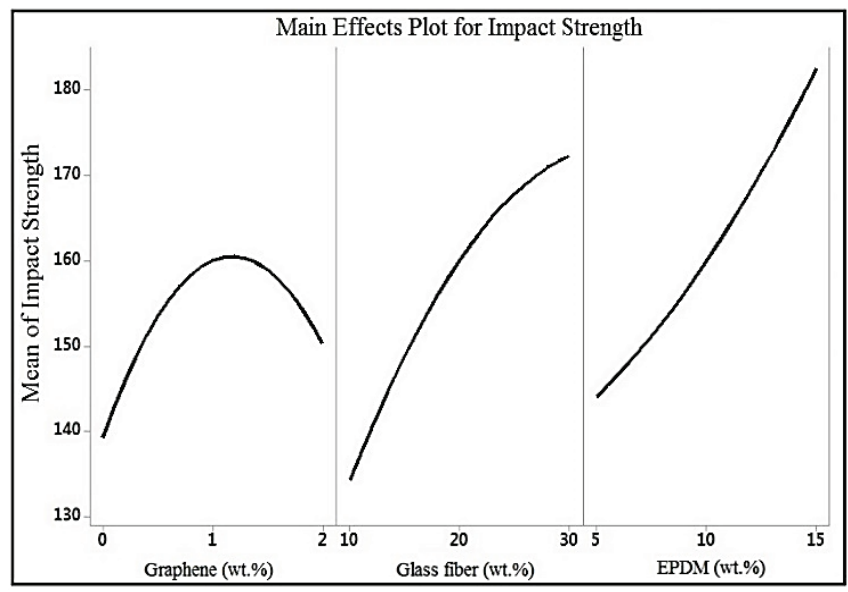

Figure 1 Main effects plot for impact strength

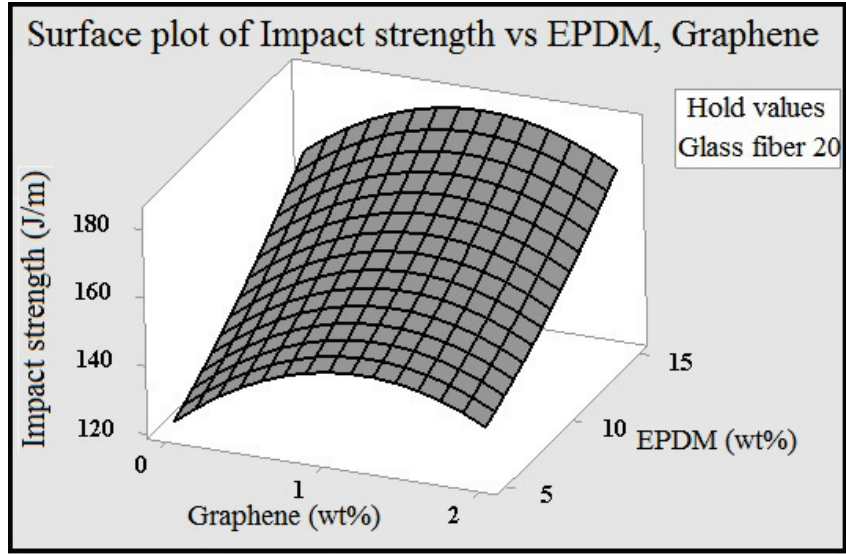

Figure 2 Impact strength versus EPDM and GnPs surface plot 
Eq. (2) was applied to create the response surface plot for the impact strength versus GnPs, glass fiber and EPDM (on wt.\%). Vertical axes of the response plots demonstrate the responses; as well as, each of the horizontal axis shows the design of variables by keeping the other one constant. For this model, if the reaction is significant, so it twisted the plane, and when the reaction is not important, the answer becomes as a flat plane. The $3 \mathrm{D}$ plots of response surface for impact strength versus $\mathrm{EPDM} \times \mathrm{GnPs}$ and $\mathrm{GnPs} \times$ glass fiber are presented in Figs. 2 and 3, respectively.

Fig. 2 shows that the more EPDM is used, the less impact strength becomes. Furthermore, adding GnPs up to $1 \mathrm{wt} . \%$, results in an increase and adding it higher than $1 \mathrm{wt} . \%$, results in a decrease in impact strength. According to Fig. 3, one sees that the impact strength significantly improved by adding glass fiber from 10 to $30 \mathrm{wt} . \%$; the highest increase in impact strength was at the middle level of GnPs (1 wt.\%).

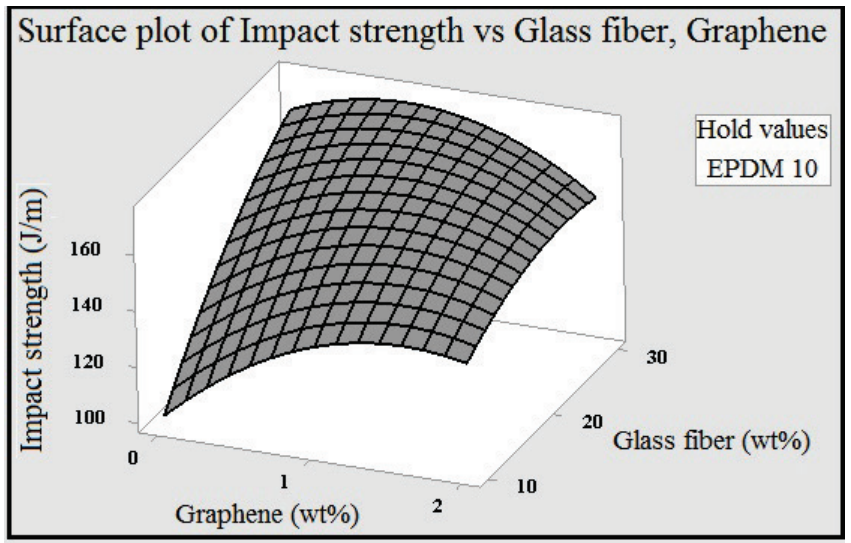

Figure 3 Impact strength versus GnPs and glass fiber surface plot

\subsection{Effects of GnPs, Glass Fiber and EPDM Content on Elastic Modulus}

Tab. 5 indicates the outcomes of ANOVA analysis to the elastic modulus. It is seen that the linear ( $\mathrm{GnPs}$, glass fiber and $\mathrm{EPDM})$, square $(\mathrm{GnPs} \times \mathrm{GnPs}$ and glass fiber $\times$ glass fiber) and interaction $(\mathrm{GnPs} \times$ glass fiber and $\mathrm{GnPs} \times \mathrm{EPDM})$ the three procedure parameters factors are considerable on the elastic modulus. The $R^{2}$ for elastic modulus shows that just $0.39 \%$ of the variation was not described by this model ( $99.61 \%$ of variations are predictive). Also, the large values of $R^{2}$ Adj $(98.90 \%)$ and $R^{2}$ Pred $(95.49 \%)$ demonstrate that the model is very predictive.

Coefficients of a second order polynomial equation, using ANOVA and multiple regression analysis, were estimated in term of real parameters as:

$$
\begin{aligned}
& \text { Elastic modulus }=650+35 X_{1}+50.75 X_{2}-17.25 X_{3}- \\
& -17.12 X_{1}^{2}+20.88 X_{2}^{2} r-23.75 X_{1} X_{2}-11.75 X_{1} X_{3}
\end{aligned}
$$

It can be seen in Eq. (3) that among all the important variables, the glass fiber $\left(X_{2}\right)$ has the biggest influence in the elastic modulus because of its higher coefficient.
Table 5 ANOVA results for elastic modulus

\begin{tabular}{|l|c|c|c|c|c|}
\hline \multicolumn{1}{|c|}{ Source } & $D F$ & Adj SS & Adj $M S$ & $F$ & $p$ \\
\hline Regression & 9 & 38665 & 4296 & 140.8 & 0.000 \\
\hline Linear & 3 & 32785 & 10928 & 358.3 & 0.000 \\
\hline GnPs & 1 & 9800 & 9800 & 321.3 & 0.000 \\
\hline Glass Fiber & 1 & 20604 & 20604 & 675.5 & 0.000 \\
\hline EPDM & 1 & 2380 & 2380 & 78.0 & 0.000 \\
\hline Square & 3 & 3029 & 1009 & 33.1 & 0.001 \\
\hline GnPs $\times$ GnPs & 1 & 1082 & 1082 & 35.5 & 0.002 \\
\hline Glass Fib $\times$ Glass Fib & 1 & 1609 & 1606 & 52.7 & 0.001 \\
\hline EPDM $\times$ EPDM & 1 & 127 & 127 & 4.1 & 0.096 \\
\hline Interaction & 3 & 2850 & 950 & 31.1 & 0.001 \\
\hline GnPs $\times$ Glass Fib & 1 & 2256 & 2256 & 73.9 & 0.000 \\
\hline GnPs $\times$ EPDM & 1 & 552 & 552 & 18.1 & 0.008 \\
\hline Glass Fib $\times$ EPDM & 1 & 42 & 42 & 1.3 & 0.292 \\
\hline$R^{2}=99.61 \%$ & \multicolumn{7}{|c|}{$R^{2}$ Adj $=98.90 \%$} & $R_{\text {Pred }}^{2}=95.49 \%$ \\
\hline
\end{tabular}

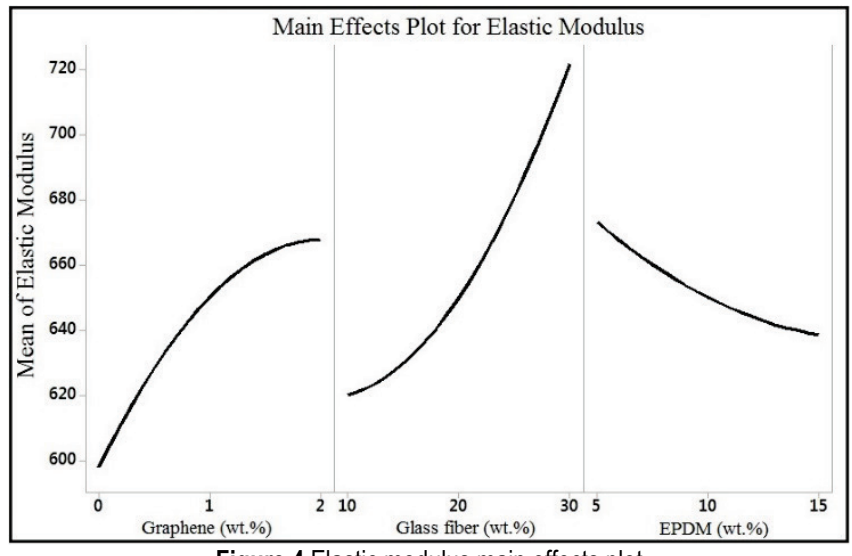

Figure 4 Elastic modulus main effects plot

The main effects plot in elastic modulus is indicated in Fig. 4. Accordingly, the addition of GnPs into PP matrix from 0 to $1 \mathrm{wt} . \%$ increased the elastic modulus of composites by $7 \%$ and, at high levels, increased it by $2 \%$. The improvement in elastic modulus by increasing of GnPs into matrix related to good adhesion between the nano sheets and matrix. The addition of GnPs in binary matrix caused the proper adhesion of nano fillers in the matrix and created stronger bonds, which increased the elastic modulus [17, 18, 25]. In addition, from Fig. 4, with increase the glass fibers increased elastic modulus by $11 \%$, the most important reason for which can be very high modulus of glass fibers and effect of transferring the load from a flexible polymer to rigid fibers [28]. Also, according to Fig. 4, the increase in EPDM reduced elastic modulus because EPDM elastomer to the PP was softer and had a lower elastic modulus.

The three dimensional plots of elastic modulus response surface versus EPDM $\times$ glass fiber, by keeping GnPs at 1 wt.\%, and EPDM $\times$ GnPs, by keeping the glass fiber at 20 wt.\%, are offered in Figs. 5 and 6, respectively. From Fig. 5, it is seen that the elastic modulus increased by increasing glass fiber from 10 to $30 \mathrm{wt} \%$; however, it decreased by increasing of EPDM from 5 to $15 \mathrm{wt} . \%$. In addition, from Fig. 5, the highest amounts of the elastic modulus were reached at the maximum level of glass fiber (30 wt.\%) and minimum level of EPDM (5 wt.\%). Fig. 6 shows that the elastic modulus increased by increasing of GnPs from 0 to 2 wt.\%; but, it decreased by increasing of EPDM from 5 to 15 wt.\%; the highest increase in the elastic modulus was at the 
high level of GnPs (2 wt.\%) and low level of EPDM (5 wt.\%).

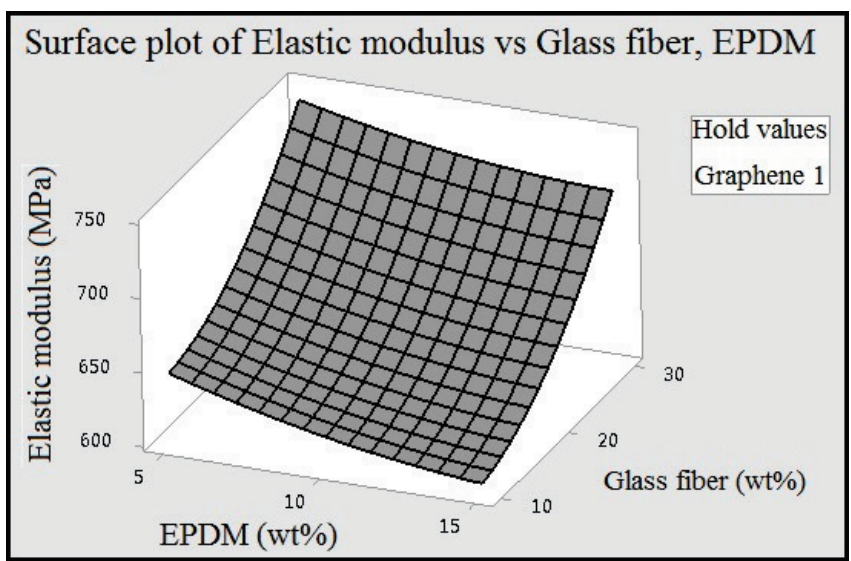

Figure 5 Elastic modulus surface plot versus EPDM and glass fiber

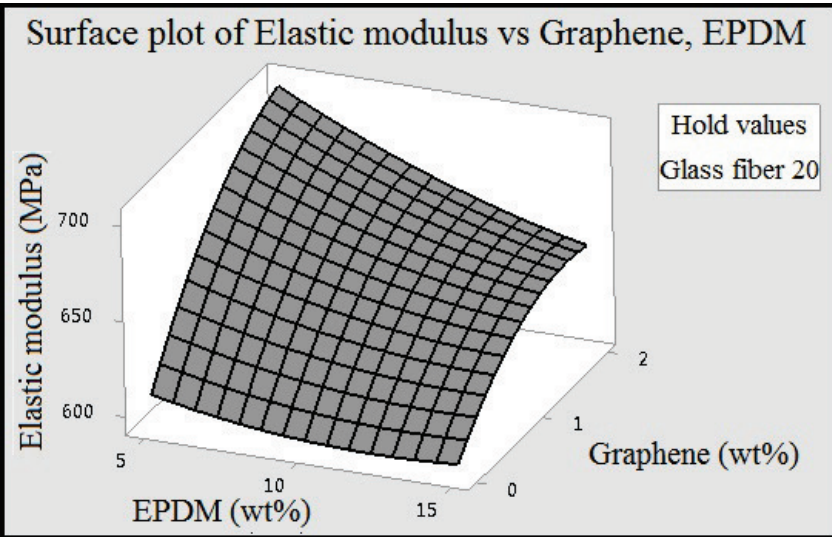

Figure 6 Elastic modulus surface plot versus EPDM and GnPs

\subsection{Maximizing of Mechanical Properties}

To optimize the mechanical properties, the impact strength and elastic modulus must be maximized together. A helpful method for solving a multiple response optimization subject is the use of the desirability function. In the method, every response equation is converted into an individual desirability function $(d)$ that its value changes within $0 \leq d \leq$ 1. Relevant to the response characteristics, there are three forms of the desirability function as follows:

(1) The higher is better - to maximize an objective function;

(2) The lower is better - to minimize an objective function;

(3) The nominal is better - to achieve a particular target, an objective function required [24].

Here, the elastic impact strength and modulus must be maximized. For this purpose, the associating desirability functions were the-higher-the-better. It can be written in a general form as presented in Eq. (4):

$$
d_{1}=\left\{\begin{array}{cc}
0 & y<L \\
\left(\frac{y-L}{T-L}\right)^{r} & L \leq y \leq T \\
1 & y>T
\end{array}\right.
$$

Where y is the response, $T$ is the objective or target of the response, $L$ shows the lower limit of the response and the super index $r$ is the weight factor [29]. When the weight factor is 1 , the desirability function will be linear. Selecting $r$ $>1$ means that it is more important to be close to the target value and choosing $0 \leq r \leq 1$ reduces its importance. Here, as two responses were studied, $r=0.5$ was selected.

Depending on the desirability of each response, the component or overall desirability value was then calculated. This component desirability function $(0 \leq D \leq 1)$ is optimized (maximized) to locate the optimal factor settings (factor combination) [24]. Overall desirability function is given by:

$$
D=\left(d_{1} d_{2} \ldots d_{n}\right)^{\frac{1}{n}}
$$

Where $n$ defines the responses number. The desirability function method was used in this work to join two responses (impact strength and elastic modulus) on a nanocomposite desirability function that may be written as:

$D=\left(d_{1}\left(\right.\right.$ impact strength $(x) \times d_{2}(\text { elastic modulus }(x))^{\frac{1}{2}}$

Where $D$ defines the nanocomposite desirability function, $d_{1}$ and $d_{2}$ are individual desirability functions related to the first and second responses (impact strength and elastic modulus), $x$ shows the vector of the designed variables (coded values), impact strength $(x)$ and elastic modulus $(x)$ are the predictor of the impact strength and elastic modulus given by the regression Eq. (2) and the Eq. (3) respectively.

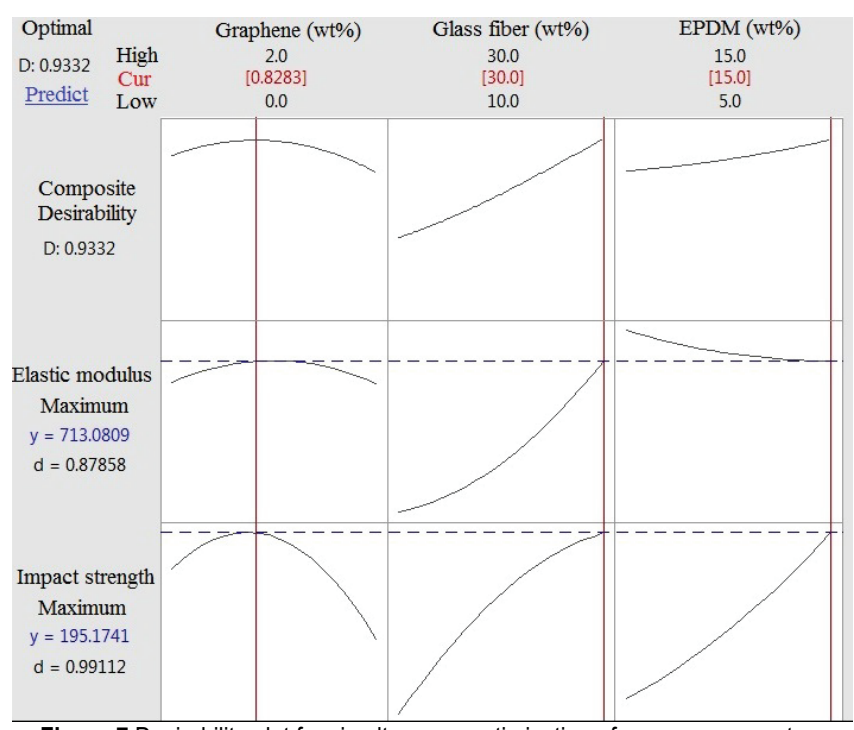

Figure 7 Desirability plot for simultaneous optimization of process parameters

The responses of desirability function analysis are presented in Fig. 7. To maximize impact strength and elastic modulus (in Fig. 7) under the best situation of nanocomposite desirability $(D=0.93)$, the amounts of GnPs must be at 0.83 wt.\%, glass fiber at $30 \mathrm{wt} . \%$ and EPDM at $15 \mathrm{wt} \%$. Moreover, the RSM design of experiments predicted that the favorable mechanical characteristics can be achieved from 
the elastic modulus equals to $713.08 \mathrm{MPa}$ and the impact strength equals to $195.17 \mathrm{~J} / \mathrm{m}$. Moreover, desirability function results indicated that the nanocomposite desirability (0.93) was exactly near to 1 that indicated the settings were appropriate to reach a good answer for each responses. Anyway, one sees that the settings were more effective for maximizing the impact strength $(d=0.991)$ than elastic modulus $(d=0.878)$.

Table 6 Validation of results for optimal conditions

\begin{tabular}{|c|c|c|c|}
\hline Mechanical properties & Prediction & $\begin{array}{c}\text { Confirmation } \\
\text { experiment }\end{array}$ & Error Percent \\
\hline Elastic modulus $(\mathrm{MPa})$ & 713.08 & 711.20 & 0.26 \\
\hline Impact strength $(\mathrm{J} / \mathrm{m})$ & 195.17 & 194.10 & 0.55 \\
\hline
\end{tabular}

After optimizing process, a verification test was done at optimal conditions. The impact strength and elastic modulus contents gained from the confirmation test were nearly similar to the data that is received from optimal value, as shown in Tab. 6 (less than 1 percent error).

\subsection{Surface Microstructure}

To study the effect of GnPs, glass fiber and EPDM content to increase the mechanical characteristics of the nanocomposites, the impact fractured surfaces of the compounds were investigated by the SEM, as indicated in Fig. 8. SEM pictures show the dispensation and adaptability among the fillers and the matrix clearly. From Fig. 8a, it is clear that the glass fibers did not have good adhesion with the field and, when applying the bending loads to fracture the samples, had an attitude to pull from the polymer matrix out. This behavior is not surprising in the composite [30].

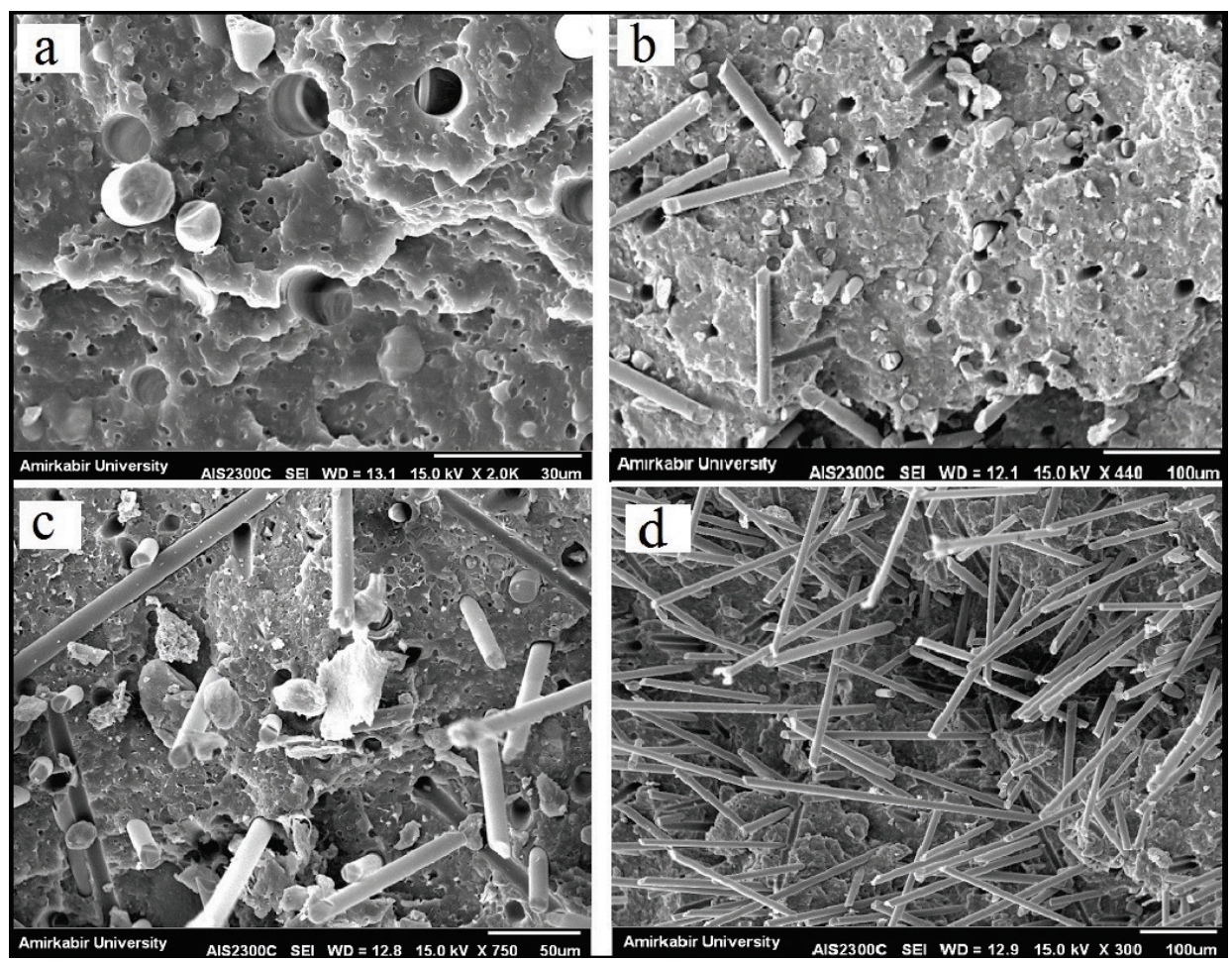

Figure 8 SEM images of the sample with: a) 0 wt. $\%$ GnPs, 10 wt. $\%$ glass fiber and 10 wt. $\%$ EPDM, b) 1 wt. $\%$ GnPs, 10 wt. $\%$ glass fiber and 5 wt. $\%$ EPDM, c) 2 wt. $\%$ GnPs, 10 wt. \% glass fiber and 10 wt.\% EPDM, d) 1 wt. $\%$ GnPs, 30 wt.\% glass fiber and 15 wt. \% EPDM.

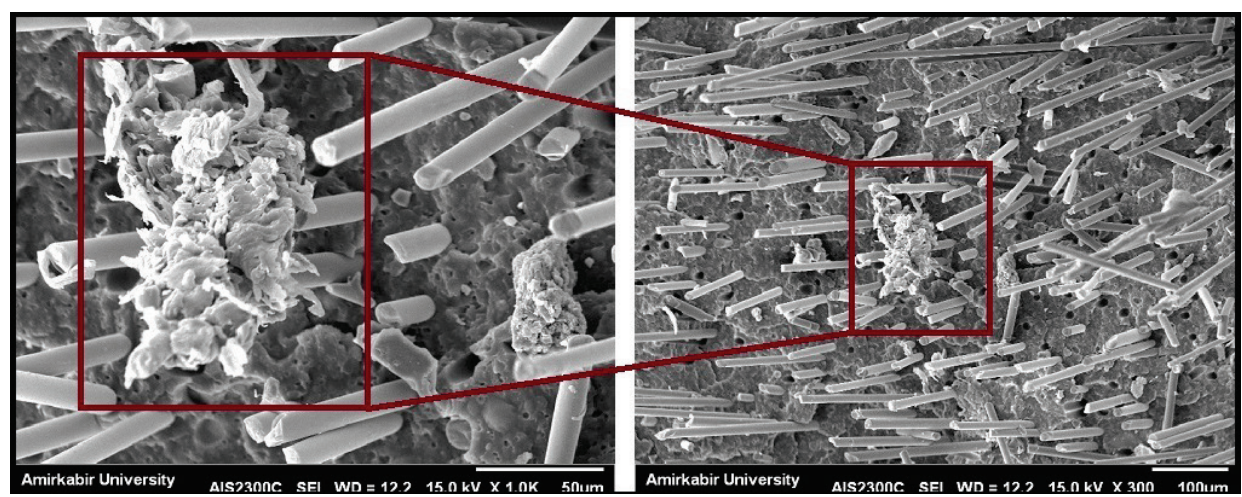

Figure 9 SEM images of the sample with $2 \mathrm{wt} . \% \mathrm{GnPs}, 20 \mathrm{wt} . \%$ glass fiber and $15 \mathrm{wt} . \%$ EPDM. 
From Fig. 8b, the convenient distribution of $1 \mathrm{wt} . \% \mathrm{GnPs}$ in the matrix could be seen. Also, the presence of $2 \mathrm{wt} . \%$ of nanoparticles in polymer matrix led to agglomeration, as is visible in Fig. 8c. Also, as can be seen in Fig. 8d, adding 1 wt.\% of GnPs in the nanocomposites caused filling the cavities in the polymer matrix and improved adhesion between the fiber and matrix. The effects of the filler on mechanical properties in the nanocomposites have also been reported in the results of other researchers [26]. In Fig. 9, one sees that, if the values of GnPs become 2 wt.\%, the nano sheets easily agglomerates. Actually, according to the van der Waals force, GnPs have high trend to agglomerate. This results in a decrease of mechanical characteristics of the nanocomposites, respect to nanocomposites filled with a less value of GnPs.

\subsection{Thermal Properties}

Figs. $10 \mathrm{a}$ and $10 \mathrm{~b}$ indicates the melting and crystallization curves related to cooling and heating cycles of two samples. The cooling curve peak illustrates the crystallization temperature $\left(T_{\mathrm{c}}\right)$ and the heating curve peak demonstrates the melting temperature $\left(T_{\mathrm{m}}\right)$ of the nanocomposites. It is visible that the both of thermal parameters related to the $T_{\mathrm{c}}$ and $T_{\mathrm{m}}$ were obtained and presented in Tab. 7. As can be seen, an increase of 1 to 2 wt. $\%$ of GnPs can increase $T_{\mathrm{c}}$ less than $2 \%$, but it did not significantly affect the $T_{\mathrm{m}}$. Increasing of the $T_{\mathrm{c}}$ of the PP matrix with the addition of GnPs up to $2 \mathrm{wt} . \%$ indicates that GnPs helped crystallize the PP. Increasing the crystallinity of polymers increases the elastic modulus. Therefore, the presence of 2 wt. $\%$ of nanoparticles increases the elastic modulus of the compounds (Fig. 4).

Table 7 Results of DSC analysis.
\begin{tabular}{|c|c|c|}
\hline Sample no & $T_{\mathrm{c}}\left({ }^{\circ} \mathrm{C}\right)$ & $T_{\mathrm{m}}\left({ }^{\circ} \mathrm{C}\right)$ \\
\hline Pure PP & 124.24 & 164.95 \\
\hline 13 & 124.49 & 165.33 \\
\hline 6 & 127.79 & 165.36 \\
\hline
\end{tabular}

In fact, when the samples were cooled from high temperature, the GnPs acted as nucleating and crystallization starts were accelerated [31].

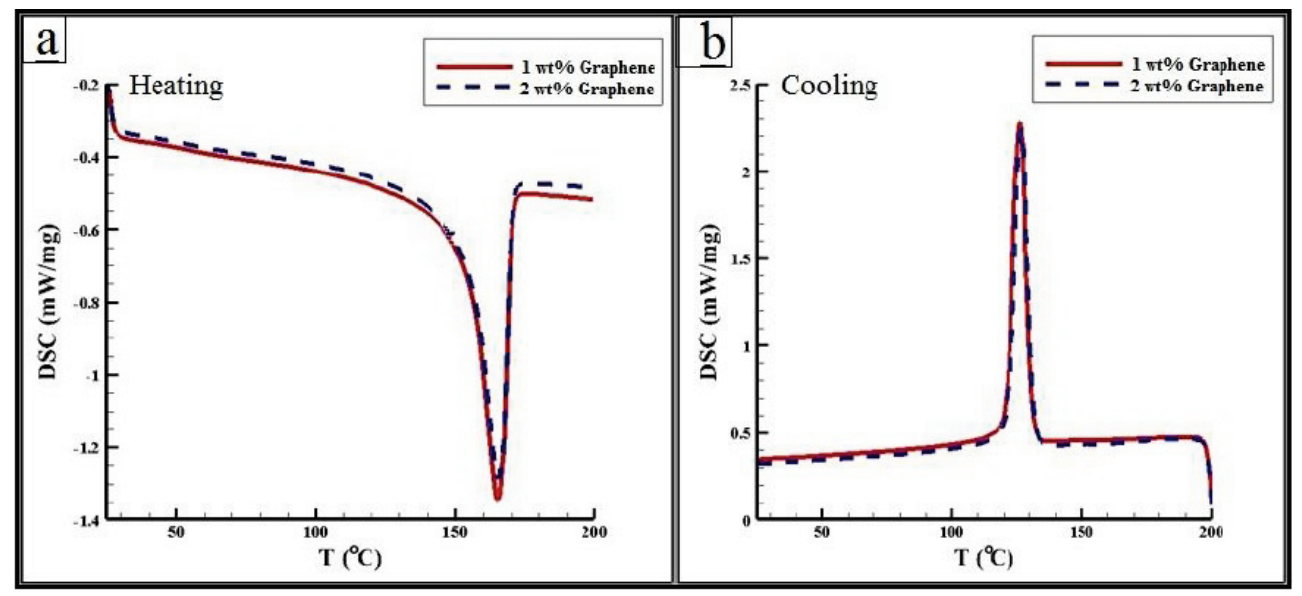

Figure 10 DSC curves: (a) heating run, (b) second cooling run.

\section{CONCLUSION}

Here, an optimization method, incorporated with a response surface methodology, a mathematical model and the desirability function approach, was used to predict and optimize the elastic modulus and impact strength of $\mathrm{PP} / \mathrm{EPDM} / \mathrm{glass}$ fiber/ GnPs polymer nanocomposites. It was found that:

1) The EPDM had the maximum influence in the impact strength and glass fiber had the most effect on the elastic modulus.

2) Embedding GnPs in the PP matrix increased the impact strength and elastic modulus by $14 \%$ and $12 \%$, respectively, but this increase was depended to the appropriate amount of used nano filler (up to $1 \mathrm{wt} . \%$ ).

3) Based on the main effects and interaction plots, increasing in EPDM contents resulted 28\% increase of the impact strength, whereas an increase in glass fiber contents results in an increase of impact strength by $25 \%$ and elastic modulus by $16 \%$.
4) According to the desirability function, ultimate impact strength and elastic modulus were forecasted as below: GnPs 0.83 wt.\%, glass fiber 30 wt.\% and EPDM 15 wt.\%.

\section{REFERENCES}

[1] Hasegawa, N., Kawasumi, M., \& Kato, M. (1998). Preparation and mechanical properties of polypropylene-clay hybrids using a maleic anhydride-modified polypropylene oligomer. J. of App. Polym. Sci, 67(1), 87-92. https://doi.org/10.1002/(SICI)10974628(19980103)67:1<87::AID-APP10>3.0.CO;2-2

[2] Kaminsky, W. \& Wiemann, K. (2006). In-situ polymerization of olefins on nanoparticles or fibers by metallocene catalysts. Compos. Interf., 13, 365-375. https://doi.org/10.1163/156855406777408557

[3] Daneshpayeh, S., Ashenai Ghasemi, F., Ghasemi, I., \& Ayaz, M. (2016). Predicting of mechanical properties of $\mathrm{PP} / \mathrm{LLDPE} / \mathrm{TiO}_{2}$ nano-composites by response surface methodology. Compos. Part. B., 84, 109-120. https://doi.org/10.1016/j.compositesb.2015.08.075 
[4] Pavlidou, S. \& Papaspyrides, D. (2008). Preparation and swelling properties of superabsorbent nanocomposites based on natural guar gum and organo-vermiculite. Pro. in polym. Sci., 33(1), 1119-1198. https://doi.org/10.1016/j.progpolymsci.2008.07.008

[5] Karger-Kocsis, J. (1999). Thermoplastic rubbers via dynamic vulcanization. Polym. Blnds. \& all., 52, 125-154. https://doi.org/10.1201/9780203742921-5

[6] Ashenai Ghasemi, F., Daneshpayeh, S., Ghasemi, I., \% Ayaz, M. (2016). An investigation on the Young's modulus and impact strength of nanocomposites based on polypropylene/linear low-density polyethylene/titan dioxide (PP/LLDPE/TiO 2 ) using response surface methodology. Polym. Bull., 73(6), 1741-1760. https://doi.org/10.1007/s00289-015-1574-2

[7] Shan, G. F., Yang, W., \& Xie, B. H. (2007). Mechanical Properties and Morphology of LDPE/PP Blends. J. of Macro. Sci.Part B: Phy., 46(5), 963-974. https://doi.org/10.1080/00222340701457253

[8] Bartlett, D. W., Barlow, J. W., \& Paul, D. R. (1982). Mechanical properties of blends containing HDPE and PP. $J$. of App. Polym. Sci., 27(7), 2351-2360. https://doi.org/10.1002/app.1982.070270704

[9] Chen, Y. \& Li, H. (2004). Effect of ultrasound on extrusion of PP/EPDM blends: Structure and mechanical properties. Polym. Eng. \& sci., 44(8), 1258-1266. https://doi.org/10.1002/pen.20121

[10] Babu, R. R., Singha, N. K., \& Naskar, K. (2010). Interrelationships of morphology, thermal and mechanical properties in uncrosslinked and dynamically crosslinked PP/EOC and PP/EPDM blends. Exp. Polym. Lett., 4(4), 197209. https://doi.org/10.3144/expresspolymlett.2010.26

[11] Coran, A. Y., Patel, R., \& Williams, D. (1982). RubberThermoplastic Compositions. Part V. Selecting Polymers for Thermoplastic Vulcanizates. Rub. Chem. \& Tech., 55(1), 116136. https://doi.org/10.5254/1.3535861

[12] Naskar, K. (2007). Thermoplastic Elastomers Based on PP/EPDM Blends by Dynamic Vulcanization. Rub. Chem. \& Tec., 80(3), 504-519. https://doi.org/10.5254/1.3548176

[13] Khalili, S. M. R., Eslami Farsani, R., \& Rafiezadeh, S. (2011). An experimental study on the behavior of PP/EPDM/JUTE composites in impact, tensile and bending loadings. J. of Reinf. Plas. \& Compos., 30(16), 1341-1347. https://doi.org/10.1177/0731684411411746

[14] Chieng, B. W., Ibrahim, N. A., \& Yunus, W. M. Z. (2012). Optimization of tensile strength of poly (lactic acid)/graphene nanocomposites using response surface methodology. PolymPlast Tech. \& Eng., 51(8), 791-799. https://doi.org/10.1080/03602559.2012.663043

[15] Sheshmani, S., Ashori, A., \& Fashapoyeh, M. A. (2013). Wood plastic composite using graphene nanoplatelets. Int. j. of bio. Macr., 58, 1-6. https://doi.org/10.1016/j.ijbiomac.2013.03.047

[16] Achaby, M. E. L., Arrakhiz, F. E., \& Vaudreuil, S. B. (2012). Mechanical, Thermal, and Rheological Properties of Graphene-Based Polypropylene Nanocomposites Prepared by Melt Mixing. Polymer Composites. Polym. Compos., 33(5), 733-744. https://doi.org/10.1002/pc.22198

[17] Yuan, B., Bao, C., \& Song, L. (2014). Preparation of functionalized graphene oxide/polypropylene nanocomposite with significantly improved thermal stability and studies on the crystallization behavior and mechanical properties. Chem. Eng. J., 237, 411-420. https://doi.org/10.1016/j.cej.2013.10.030

[18] Song, P., Cao, Z., \& Cai, Y. (2011). Fabrication of exfoliated graphene-based polypropylene nanocomposites with enhanced mechanical and thermal properties. Polym., 52(18), 4001-4010. https://doi.org/10.1016/j.polymer.2011.06.045

[19] Raghavendra, M., Manjunatha, C. M., \& Peter, M. J. (2004). Effect of the moisture on the mechanical properties of GFRP composite fabric material. International Symposium of Research Students on Material Science and Engineering, Chennai. India, 20-22.

[20] Pegoretti, A., Fidanza, M., \& Migliaresi, C. (1998). Toughness of the fiber/matrix interface in nylon-6/glass fiber composites. Compos. Part. A., 29(3), 283-291. https://doi.org/10.1016/S1359-835X(97)00079-1

[21] Laura, D. M., Keskkula, H., \& Barlow, J. W. (2002). Effect of glass fiber surface chemistry on the mechanical properties of glass fiber reinforced, rubber toughened nylon 6. Polym., 43 (17), 4673-4687. https://doi.org/10.1016/S0032-3861(02)00302-6

[22] Güllü, A., Özdemir, A., \& Özdemir, E. (2006). Experimental investigation of the effect of glass fibres on the mechanical properties of polypropylene (PP) and polyamide 6 (PA6) plastics. Mat. \& Des., 27(4), 316-323. https://doi.org/10.1016/j.matdes.2004.10.013

[23] Zare, Y., Garmabi, H., \& Sharif, F. (2011) Optimization of mechanical properties of $\mathrm{PP} /$ nanoclay $/ \mathrm{CaCO}_{3}$ ternary nanocomposite using response surface methodology. J. of appl. Polym. Sci., 122(5), 3188-3200. https://doi.org/10.1002/app.34378

[24] Montgomery, D. C. (2001). Design and analysis of experiments. New York, John Wiley.

[25] Chaharmahali, M., Hamzeh, Y., Ebrahimi, G., \& Ashori, A. (2014). Effects of nanographene on the physico-mechanical properties of bagasse/polypropylene composites. Polym. Bull., 71(2), 337-349. https://doi.org/10.1007/s00289-013-1064-3

[26] Mohedi, A. H., Liaghat, G. H., \& Pol, M. H. (2015). Experimental study on the effect of nano-silica composite interlaminar fracture toughness third of materials reinforced with glass fiber. Mod. Mechanic. Eng., 15, 283-290. (In Persian)

[27] Thomason, J. L. (2002). Influence of fiber length and concentration on the properties of glass fiber-reinforced polypropylene: 5. Injection moulded long and short fiber PP. Compos. part A., 38(1), 210-216. https://doi.org/10.1016/j.compositesa.2006.01.007

[28] Rahman, N. A., Hassan, A., \& Yahya, R. (2013). Impact Properties of Glass fiber/polypropylene Composites: The Influence of Fiber Loading, Specimen Geometry and Test Temperature. Fib. \& Polym., 14(11), 1877-1885. https://doi.org/10.1007/s12221-013-1877-6

[29] George, E., Hunter, J. S., \& Hunter, W. G. (2005). Statistics for experimenters: design, innovation and discovery. $4^{\text {th }}$ ed. New York, John Wiley \& Sons.

[30] Galli, P., Danesi, S., \& Simonazzi, T. (1984). Polypropylene based polymer blends: fields of application and new trends. Polym. Eng. Sci., 24(8), 544-554. https://doi.org/10.1002/pen.760240807

[31] Ashenai Ghasemi, F., Ghasemi, I., \& Daneshpayeh, S. (2014). Mechanical and thermal properties of nanocomposites based on polypropylene/linear low density polyethylene/Titanium dioxide. Mod. Mechanic. Eng. 14, 103-109. (In Persian)

\author{
Authors' contacts: \\ Meysam Nouri Niaraki \\ Faculty of Mechanical Engineering, Semnan University, \\ Central Administration of Semnan University, \\ Campus 1, Semnan, Iran \\ Tel: $+9823-33654100$ \\ meysam_nouri05@yahoo.com
}


Faramarz Ashenai Ghasemi

(Corresponding author)

Faculty of Mechanical Engineering,

Shahid Rajaee Teacher Training University,

Shabanloo St., Lavizan, Tehran, Iran

Tel: +9821-22970060

f.a.ghasemi@sru.ac.ir

faramarz_ashenai_ghasemi@yahoo.com

\section{Ismail Ghasemi}

Department of Polymer Processing,

Polymer and Petrochemical Institute (IPPI),

$15 \mathrm{~km}$ Tehran-Karaj Highway,

Pajuhesh Science and Technology Park,

Pajuhesh Boulevard, Tehran, Iran

Tel: +9821-44787050

I.Ghasemi@ippi.ac.ir

Sajjad Daneahpayeh

Faculty of Mechanical Engineering,

Shahid Rajaee Teacher Training University,

Shabanloo St., Lavizan, Tehran, Iran

Tel: +9821-22970060

sajad_danesh66@yahoo.com 